Beata Strzemiecka*, Károly Héberger, Adam Voelkel, Similarity and grouping of perlite and zeolite abrasive fillers. A replacement test, Journal of Applied Polymer Science 127 /5/ 3839-3847 (2013) published online: 23 May 2012; DOI: 10.1002/app.37695

(C) 2012 Wiley Periodicals, Inc.

WWW.MATERIALSVIEWS.COM WILEYONLINELIBRARY.COM/APP

\title{
Similarity and grouping of perlite and zeolite abrasive fillers. A replacement test
}

\author{
Beata Strzemiecka ${ }^{1}$, Károly Héberger ${ }^{2}$, Adam Voelkel ${ }^{1}$ \\ ${ }^{1}$ Poznan University of Technology, Institute of Chemical Technology and Engineering, Pl. \\ M. Sklodowskiej-Curie 2, 60-965 Poznan, Poland; \\ ${ }^{2}$ Chemical Research Center, Hungarian Academy of Sciences, \\ Pusztaszeri út 59/67, Budapest, H-1025, Hungary
}

\begin{abstract}
Inverse Gas Chromatography was used to estimate surface activity expressed by the dispersive component of the surface free energy, $\gamma_{S}^{D}$, as well as parameters $K_{A}$ and $K_{D}$ describing surface ability to act as electron acceptor and donor, respectively. These parameters characterize the ability of the surface to specific interactions. The method was also applied to describe the magnitude of filler-phenolic resin interaction by Flory-Huggins parameter, $\chi_{23}^{\prime}$. Granulation, surface area and porosity were also determined.

The minimum number of parameters required to complete characterization of filler properties has been selected by principal component analysis. The usefulness of the selection for the abrasive industry has been proven. Moreover, the similarities and deviations from "an average" filler was determined by chemometric methods.

Principal component analysis (PCA) and a novel procedure based on sum of ranking differences (SRD) were successfully applied for selection of the best fillers, and of advantageous parameters for characterization of the fillers. Similar and diverse fillers have been chosen based on clustering pattern by PCA and SRD.
\end{abstract}




\section{Introduction}

Abrasive articles consist of cutting particle (i) very often from electrocorundum, filler (ii) inorganic compound (pyrite or lithopone), binder (iii) novolac resin and wetting agent, resol. The fillers play important role during production and in the work of the grinding tools, and can influence cross-linkage of resins during manufacturing of the abrasive article. Moreover, they collect the heat and prevent the melting of resin while the grinding tool works. Consequently, fillers affect the hardness of the final product. The influence of the type of the filler on the hardening process by differential scanning calorimetry (DSC) was also studied [1]. Commonly used fillers in abrasive industry can emit hazardous compounds for example pyrite $\left(\mathrm{FeS}_{2}\right)$ emits dangerous sulphur compounds. It was the main reason for searching new proecological fillers that are stable during work of grinding tool. The aluminosilicates such as perlites and zeolites were chosen for our investigations as being nontoxic, pro-ecological fillers fulfilling all technological requirements.

During heating perlites formed microblisters of irregular shapes and contain air. The process is called expanding (swelling) and the resulting product is called expanded perlite [2 4].

Surface activity of the fillers plays crucial role during manufacturing and further usage of the grinding tool. Surface activity influences fillers ability to mix, e.g. with resol and to form "homogenous" mixture. It affects also the strength of the interactions between fillers and both resins: novolac and resol.

The crucial parameters characterizing potential fillers are granulation (size of particle grains) and surface activity. The last can be expressed, e.g., by the dispersive component of the surface free energy, $\gamma_{S}^{D}$, as well as parameters $K_{A}$ and $K_{D}$ describing surface ability to act as electron acceptor and donor, respectively. These parameters characterize the ability of the surface to participate in specific interactions. $K_{A}+K_{D}$ parameters expresses the total surface 
ability to specific interactions, i.e. both ability to act as electron acceptor and donor. The surface area $\left[\mathrm{m}^{2} / \mathrm{g}\right]$; porosity: volume and size of pores; susceptibility to atmospheric conditions such as: temperature, humidity should also be taken into account during the selection of the material.

Inverse Gas Chromatography (IGC) has earlier been applied for surface characterization of studied fillers. This technique was presented in number of reviews [5-9]. IGC is an extension of the classical gas chromatography. Inverse gas chromatography characterizes the surface of any material, which is placed in the chromatographic column. Carefully selected test compounds, with known physicochemical properties, are injected into the column. Retention data are suitable to calculate parameters describing surface properties its activity expressed by $\gamma_{S}^{D}, K_{A}, K_{D}$ and $K_{A}+K_{D}$ parameters. IGC was also applied to describe filler-phenolic resin interaction by Flory-Huggins parameter, $\chi_{23}^{\prime}$. The experimental data were analyzed by chemometrics methods: principle component analysis (PCA) and a novel procedure based on sum of ranking differences (SRD).

The aim of the paper was to elaborate a replacement test for abrasive fillers. For this purpose we have to find similarities and dissimilarities among fillers. The pattern will be revealed by an unsupervised pattern recognition technique: by principal component analysis. The fillers were also ordered by a novel technique based on sum of ranking differences. As reference (benchmark) for ranking the average was used. Such a way the most common (average) filler can be selected, and similarly, the most deviating ones can be determined besides the grouping patterns. On the other hand the number of test compounds is to be diminished still preserving the full characterization of fillers (pattern in the data) remains as a precious aim. 


\section{Experimental}

\section{Materials}

Examined fillers are presented in Table 1. Standard fillers (lithopone, calfix, pyrite) were compared with new ones: pyrites and zeolites. All fillers were supplied by Certech Niedomice (Poland) and used as supplied. Resol resin used to study resin-filler interactions was supplied by ZTS Erg S.A. (Poland). It was liquid, aqueous resin (6\% w/w of water) with viscosity $1500-2000 \mathrm{cP}$ at $20^{\circ} \mathrm{C}$.

\section{IGC experiments}

IGC measurements were carried out by using SRI 8610C gas chromatograph produced by SRI Instruments (USA) equipped with flame ionization detector. Carrier gas was helium with flow rate $15.7 \mathrm{ml} / \mathrm{min}$. Teflon (PTFE) columns, I.D. $4 \mathrm{~mm}$ were used. Their length was $28 \mathrm{~cm}$ during examination of the aluminosilicates and standard fillers, while in IGC experiments with the resin and filler-resin mixture $68 \mathrm{~cm}$ columns were used. The column filling for the examination of potential and standard fillers was prepared by covering glass microballs with the powder to obtain homogeneous layer of the examined material. The column filling for examination filler-resin interactions was prepared by covering glass microballs with resin and following mixing with the appropriate amount of the filler.

All columns were conditioned overnight at the flow-rate and temperature used later during IGC experiments. The measurements were carried out at 30 and $120^{\circ} \mathrm{C}$, injector and detector temperature was $150^{\circ} \mathrm{C}$. All columns were conditioned $2 \mathrm{~h}$ at the flow-rate and temperature used later during IGC experiments. Vapours of test compounds were injected in the amount ensuring the achievement of the infinite dilution region. Applied test compounds can be divided into two categories:

- non-polar ones: pentane, hexane, heptane, octane, nonane;

- polar compounds: ethanol, acetone, 1,4-dioxane, chloroform, 1,2-dichloroethane, acetonitrile.

These compounds were of analytical grade and supplied by Sigma Aldrich, Fluka, Chempur and Acros Organics.

$\gamma_{S}^{D}$, the dispersive of component of surface free energy of the examined solid material, was calculated from the following equation:

$$
R \cdot T \cdot \ln V_{N}=2 \cdot N \cdot a_{p} \cdot \sqrt{\gamma_{S}^{D} \cdot \gamma_{L}^{D}}+C
$$


where: symbol $\gamma_{L}^{D}$ denotes the dispersive of component of surface free energy of the test solute; symbol $a_{p}$ denotes the area occupied by an adsorbing molecule and $V_{N}$ is the net retention volume of the test solute. $\gamma_{S}^{D}$ is calculated from the slope of the straight line.

$K_{A}$ and $K_{D}$ parameters expressing electron acceptor and electron donor properties, respectively were calculated from equation (2)

$$
\Delta H_{i}^{s}=D N_{i} \cdot K_{A}+A N_{i}^{*} \cdot K_{D}
$$

$\Delta H_{i}^{s}$ is the specific component of enthalpy of adsorption of polar compound " $\mathrm{i}$ " related to socalled acceptor and donor numbers $[6,7,10,11]$ describing the electron acceptor $\left(A N^{*}\right)$ $[\mathrm{kJ} / \mathrm{mol}]$ and electron donor $(D N)[\mathrm{kJ} / \mathrm{mol}]$ properties of the test solute " $\mathrm{i}$ ".

$\chi_{23}^{\prime}$ was calculated from the following equation

$$
\chi_{23}^{\prime}=\frac{1}{\varphi_{2} \cdot \varphi_{3}} \cdot\left(\chi_{12}^{\infty} \cdot \varphi_{2}+\chi_{13}^{\infty} \cdot \varphi_{3}-\chi_{1 m}^{\infty}\right)
$$

using $\chi_{12}^{\infty}$ and $\chi_{13}^{\infty}$ values determined earlier for binary mixtures according to eq. (4).

$$
\chi_{1 m}^{\infty}=\ln \left(\frac{273.15 \cdot R}{p_{1}^{o} \cdot V_{g} \cdot M_{1}}\right)-\frac{p_{1}^{o}}{R^{*} T} \cdot\left(B_{11}-V_{1}^{o}\right)+\ln \left(\frac{\rho_{1}}{\rho_{m}}\right)-\left(1-\frac{V_{1}^{o}}{V_{2}^{o}}\right) \cdot \varphi_{2}-\left(1-\frac{V_{1}^{o}}{V_{3}^{o}}\right) \cdot \varphi_{3}
$$

where: 1 denotes the solute and 2, 3 or $m$ denotes examined material (component 2, component 3 or their mixture), $M_{1}$ is the molecular mass of the solute, $p_{1}^{o}$ is the saturated vapor pressure of the solute, $B_{11}$ is the second virial coefficient of the solute, $V_{i}^{o}$ is the molar volume, $\rho_{\mathrm{i}}$ is the density, $R$ is the gas constant; $\varphi_{2}$ and $\varphi_{3}$ are the volume fractions of components.

The surface area $\left[\mathrm{m}^{2} / \mathrm{g}\right]$ and porosity (the volume and size of pores) of fillers were determined by using of BET method. Accelerated Surface Area and Porosimetry Analyzer ASAP 2020 produced by Micromeritics Instruments Co was used. The experiment was based on liquid nitrogen adsorption. Examined samples were degassed at elevated temperature in a vacuum chamber.

\section{Table 1}

\section{Principal component analysis (PCA)}

PCA is an unsupervised pattern recognition method, it can also be considered as a dimension reduction one. The original high dimensional data are projected in a much smaller 
dimensional subspace. Several principal components are retained while explaining a large portion of variance in the data. The technique of PCA can be found in standard chemometric books and reviews, e.g. refs $[12,13]$. Principal components are arranged successively in decreasing order of eigenvalues accounting for decreasing amounts of variance. The coefficients between the original and new variables are called the loadings. They explain how the new PCs are composed from the original variables. PCA is particularly useful for classification of IGC data [14] and evaluation of stationary phases and polarity parameters [15].

\section{Sum of ranking differences (SRD) and its validation}

The new ordering method has been described earlier, [16] and its validation has been published soon thereafter, [17]. SRD ordering is based on comparisons of rank numbers. Always the rank numbers of the actual and a reference (benchmark) ranks are compared (the rank numbers are subtracted and their absolute values are built and added together for each systems). Such a way all fillers can be compared (t, e, p, .. zf, ... etc. ...) each of them receives an SRD value. The smaller the SRD value the "better" i.e. the less discrepancy can be observed as compared to the reference ranking. The ordering is given by the test compounds for characterization (rows). Generally, the row averages of fillers are selected as benchmark. However, such reference would rank the fillers by average, i.e. $s$ the best filler is the "mean" one, which can substitute all of them at best. The proximity of SRD values will show the similarity among fillers, the filler with the largest SRD value is the most deviating one from all the others.

\section{Results}

\section{1) Evaluation of the retention data}


Retention data of test solutes and fillers are summarized in Tables 2. Table 2 contains retention data of selected test solutes used in IGC experiments.

Table 2

Notation for the respective objects and variables is given therein. The retention times for test solutes were examined first, as these data were further used for calculation of IGC parameters presented in Table 3.

PCA indicates that retention data for almost all test solutes should be taken into account with exceptions: heptane at $35^{\circ} \mathrm{C}(\mathrm{h} 35)$ and ethyl acetate at $35^{\circ} \mathrm{C}$ (ea35). At least three significant principal components should be retained according to a scree plot (not shown). The first one consists of multiple elements, retention data for the series of test solutes while second and third PCs are "unique" as PC 2 contains only octane at $35^{\circ} \mathrm{C}(\mathrm{o} 35)$ and PC 3 just ethyl acetate at $120^{\circ} \mathrm{C}$ (ea120). Three factors explained more than $97 \%$ of the total variance.

Analysis of loading plots (Figure 1) assure that information carried by the retention data for pentane (p), hexane (x), heptanes (h), octane (o) and chloroform (c) at $120^{\circ} \mathrm{C}$ is very similar. It means that there is no need to repeat IGC experiment for all these test solutes and one may reduce their number and having the same clustering pattern in the principal components (scores). Although information from ea35 and h35 is somewhat different from other test solutes, it is much less important. Therefore, one may eliminate these two test solutes as well.

Figure 1

Similar conclusion may be achieved from analysis of tree diagram (dendogram) for original variables. Three well separated clusters can be seen on the dendogram. Retention data carry similar information for $\mathrm{p}, \mathrm{x}, \mathrm{h}, \mathrm{o}, \mathrm{c}$ at $120^{\circ} \mathrm{C}$. Eventually e120 might be added to this group. Please, do note that most often retention data collected from IGC experiments at $120^{\circ} \mathrm{C}$ might be omitted without considerable loss of information. 
Figure 2

Perlite 150 presents most average properties of all studied fillers taking into account retention data. Most different from other fillers is pyrite probably due to its chemical composition (Table 1). Perlites reveal different properties, e.g. perlite EP200 is different from other perlites and it can not be easily explained. Perlites' surface may have complex structure and its properties may depend on many factors.

SRD orders and groups the fillers in a natural way (Figure 3). The transpose of the Table 2 has been applied here. The average retention data (row average) has been used as benchmark for ranking. The most similar filler to the average is perlite 150 . This information can be used for replacement of fillers. On the other hand the most dissimilar filler is pyrite (p). If some task cannot be solved by an "average" filler it is worth to select the most dissimilar one. Some groupings can also be observed (cluster 1: perlite 150, zeolite micro50, perlite EP150, zeolite micro20, lithopone, perlite EXP50, perlite class A thick, calfix; cluster 2: zeolite ZC20, perlite EP180, perlite PERMON85 zeolite thick and cluster 3: egzotul, perlite EP200, zeolite fine and pyrite). The first group consists of the majority of fillers. This means that most of inorganic materials represent similar surface properties. Zeolites micro20 and micro50 as well as five types of perlites and have similar surface characteristics (regarding retention data) as two standard fillers: lithopone and calfix. Lithopone and calfix are most common fillers used for manufacturing of abrasive articles. It means that the new fillers can be interesting alternatives for standard fillers used in grinding tools.

The closeness of lines in Figure 3 shows the replacement possibilities.

Figure 3

Score plots of principal component analysis also show the groupings of fillers (Figures $4 \mathrm{a}, 4 \mathrm{~b}$ and $4 \mathrm{~s})$.

Figures $4 \mathrm{a}, 4 \mathrm{~b}$ and $4 \mathrm{c}$

The following objects were selected as outliers when the retention times of test solutes were taken into account: Calfix (c), PERMON85 (p85) and zeolite fine (zf) (see Figures 4). The pattern observed by PCA confirms results obtained from SRD. Calfix as outlier might be 
surprising and hardly explainable but one should take into account also its position into SRD ordering (see Fig. 3), i.e. at the end of the first group.

\section{2) Evaluation of the physicochemical parameters}

The fillers were also characterized by a series of surface parameters. The parameters are given in Table 3. It is worth to note that $K_{A}$ and $K_{D}$ parameters are differently dependent on the temperature, i.e. for various fillers their values increase or decrease. This phenomenon might be, probably, explained by the content moisture residue in the examined materials despite the careful conditioning of filler samples.

Table 3

PCA of these physicochemical data indicates close proximity of points in Figure 5, i.e. several parameters might be omitted during characterization of fillers, while preserving the same clustering pattern. Three significant PCs should be retained in the model. The first one consists of multiple components - surface characteristics derived from IGC experiments and two "traditional ones: BET and pore volume (Vp). The second PC contains three elements while the third one is a "unique" one consisting of pore size parameter ( $\mathrm{Sp}$ ) solely. These three PCs explained more than $83 \%$ of the total variance.

Analysis of loading plots for surface parameters assure that (Figure 5) information carried by surface parameters determined at $35^{\circ} \mathrm{C}$ is sufficient. The parameters estimated at $120^{\circ} \mathrm{C}$ might be omitted as that of determined at $35^{\circ} \mathrm{C}$ can be successfully used for the description of fillers' behavior also at elevated temperature. It means that one should use the set of the following parameters for characterization of the fillers: i) IGC derived parameters $\gamma_{z}^{D}(\mathrm{~g} 35)$ or $\chi_{23}$ at $35^{\circ} \mathrm{C}(\mathrm{kh} 35), K_{A}$ at $35^{\circ} \mathrm{C}(\mathrm{Ka} 35)$ or $K_{A}+K_{D}$ at $35^{\circ} \mathrm{C}(\mathrm{K} 35)$; ii) $\mathrm{BET}$, pore volume (Vp) and pore size $(\mathrm{Sp})$.

Figure 5 
Analysis of a tree diagram for variables (surface parameters data) (Figure 6) indicates that IGC derived parameters and pores volume carry similar information. It is different from this one provided by "standard" surface characteristics, i.e. surface area (BET) and pore size $\left(\mathrm{S}_{\mathrm{p}}\right)$. This means that it is possible to deduce on resin-filler interactions on the basis of parameters describing activity of the fillers surface $\left(\gamma_{z}^{D}, K_{A}, K_{D}\right)$.

SRD orders and groups the fillers in a natural way (Figure 7). Zeolit fine and thick are most different from other fillers when surface characteristics are taken into account. Perlites exhibit medium properties described by physicochemical data. Medium means here different (lower or higher) values of surface parameters in comparison to other groups of fillers. Similar results were obtained from SRD ordering on the basis of retention data.

Figure 7

The analysis based on the values of parameters characterizing surface activity properties of the examined fillers lead to the selection of zeolite fine (zf) and zeolite thick (zt) as evident outliers (Figures $8 \mathrm{a} 8 \mathrm{~b}$ and $8 \mathrm{c}$ ). However, the group of outliers might be extended although the decision is less questionable. These additional outliers are Calfix (c), Lithopone (l) and pyrite (p). The other two "candidates" are p50 (Perlite EXP50) - the expanded perlite and probably p85 (PERMON85). It means that based on two series of experimental data the three fillers (Calfix (c), PERMON85 (p85) and zeolite fine (zf)) were selected as exhibiting different properties as other ones. However, the selection based on surface parameters seems to be more "selective". score3 vs. score2 scatterplot (Figures 8a 8b and 8c) shows two groups clear groups of fillers: perlites in upper left corner of this figure and zeolites in upper right corner of the same plot

Figures $8 \mathrm{a} 8 \mathrm{~b}$ and $8 \mathrm{c}$

The above statements suggest the clear selection into three groups: zeolites, perlites and "classic" fillers having similar properties 
zeolites

$$
\gamma_{S}{ }^{D} 35^{\circ} \mathrm{C} \quad 74-122 \mathrm{~mJ} / \mathrm{m}^{2}
$$

perlites

$$
\gamma_{S}^{D} 35^{\circ} \mathrm{C} \quad 36-65 \mathrm{~mJ} / \mathrm{m}^{2}
$$

classic fillers

$$
\gamma_{S}{ }^{D} 35^{\circ} \mathrm{C} \quad 52-72 \mathrm{~mJ} / \mathrm{m}^{2}
$$

These last data might be used to calculate the average value for "standard" (e.g. classic fillers) and used for comparison with other groups.

\section{Conclusions}

Three pattern recognition methods (principal component analysis, cluster analysis, and sum of ranking differences) group the fillers in an unambiguous way. These methods enable us to select new, proecological materials having physicochemical properties close to standard fillers, which might be used in abrasive tools. The new fillers can be: zeolite micro 20 and micro 50 and almost all of studied perlites. Zeolites can be better fillers in abrasive tools than standard ones and perlites due to their powder form and their higher surface activity. The additional advantage might be the ability of zeolites and perlites to emit water during polishing or cutting processes, i.e. acting as cooling medium. However, it was not the aim of the present work.

Sum of ranking differences can serve as a replacement test, the close proximity of lines suggest very similar characters of fillers, i.e they are interchangeable.

Cluster analysis, principal component analysis were applied to optimize number of test compounds used in IGC method. This will shorten the time of experiment and allows the quick information for technologists on the properties of raw materials and semi-products during the manufacturing of abrasive articles.

\section{Acknowledgement}

This work was supported Polish-Hungarian exchange program of the Polish and Hungarian Academies of Sciences for Years 2011-2013 and N N209 108939 grant. 


\section{References:}

1. Voelkel, A., Strzemiecka, B. Int. J. Adhes. Adhes. 2007, 27, 188-194.

2. Breck, D. W. Zeolite Molecular Sieves; J. Wiley, Int. Publ.: New York, 1974.

3. Lowell, S., Shields, J. E. Characterization of porous solids and powders: surface area, pore size and density; Kluwer Academic Publisher: The Netherlands, 2004.

4. Yang, R. T. Adsorbents: fundamentals and applications. John Wiley \& Sons, Inc.: New Jersey, 2003.

5. Thielmann, F. J. Chromatogr. A 2004, 1037(1-2), 115-123.

6. Voelkel, A., Strzemiecka, B., Adamska, K., Milczewska, K. J. Chromatogr. A 2009, 1216(10), 1551-1566.

7. Belgacem, M. N., Gandini, A. In Interfacial Phenomena in Chromatography; Pefferkorn, E., ed; Marcel Dekker, Inc.: New York, 1999; p. 41.

8. Santos, J. M. R. C. A., Guthrie, J. R. Mater. Sci. Eng. R 2005, 50(3),79-107.

9. Voelkel, A., Strzemiecka, B., Adamska, K., Milczewska, K., Batko, K. In: Polymeric Materials, Nastasovic, A., Jovanovic, S., eds; Research Signpost: Kerala, 2009; p. 71.

10. Gutmann, V., The donor-Acceptor Approach to Molecular Interactions, Plenum Press: New York, 1978.

11. Riddle, F. L., Fowkes, F. M. J. Am. Chem. Soc. 1990, 112, 3260-3264.

12. Malinowski E.R., Factor Analysis in Chemistry, second ed., John Wiley and Sons: New York, 1991.

13. Wold, S., Esbensen, K., Geladi, P. Chemometr. Intell. Lab. Syst. 1987, 2, 37-52.

14. Voelkel, A., Milczewska, K., Heberger, K. Anal. Chim. Acta 2006, 559, 221-226.

15. Héberger, K. Chemometr. Intell. Lab. Syst. 1999, 47, 41-49.

16. Héberger K. Sum of ranking differences compares methods or models fairly TRAC, Trends in Anal. Chem. 2010, 29, 101-109.

17. Héberger, K., Kollár-Hunek, K. J. Chemometr. 2011, 25, 151-158. 
Table 1

Studied materials

\begin{tabular}{|c|c|c|c|}
\hline Material & Notation & & $\begin{array}{c}\text { Moisture } \\
\text { content [\% of } \\
\text { weight] }\end{array}$ \\
\hline Lithopone & 1 & $\begin{array}{l}\text { standard fillers } \\
\text { used for } \\
\text { production of } \\
\text { abrasive articles } \\
\text { nowadays }\end{array}$ & 0.2 \\
\hline Calfix & $\mathrm{c}$ & $\begin{array}{l}\text { standard fillers } \\
\text { used for } \\
\text { production of } \\
\text { abrasive articles } \\
\text { nowadays }\end{array}$ & 0.2 \\
\hline Pyrite & $\mathrm{p}$ & $\begin{array}{l}\text { standard fillers } \\
\text { used for } \\
\text { production of } \\
\text { abrasive articles } \\
\text { nowadays } \\
\end{array}$ & 2.8 \\
\hline Egzotul & $\mathrm{e}$ & bentonite & 0.6 \\
\hline PERMON85 & $\mathrm{p} 85$ & perlite & 5.0 \\
\hline $\begin{array}{l}\text { Perlite } \\
\text { EXP50 }\end{array}$ & p50 & perlite & 1.0 \\
\hline Perlite-150 & p150 & perlite & 1.2 \\
\hline Perlite EP150 & ep150 & perlite & 0.8 \\
\hline Perlite EP180 & ep180 & perlite & 0.9 \\
\hline Perlite EP200 & ep200 & perlite & 0.8 \\
\hline $\begin{array}{c}\text { Perlite class } \\
\text { A thick }\end{array}$ & $\mathrm{pA}$ & perlite & 0.3 \\
\hline Zeolite fine & $\mathrm{zf}$ & zeolite & 10.8 \\
\hline Zeolite thick & $\mathrm{zt}$ & zeolite & 11.0 \\
\hline $\begin{array}{l}\text { Zeolite } \\
\text { micro20 }\end{array}$ & $\mathrm{zm} 20$ & zeolite & 6.2 \\
\hline $\begin{array}{l}\text { Zeolite } \\
\text { micro50 }\end{array}$ & $\mathrm{zm} 50$ & zeolite & 6.2 \\
\hline Zeolite ZC20 & ZC20 & zeolite & 5.9 \\
\hline
\end{tabular}


Table 2

Retention times [min] for test solutes at 35 and $120^{\circ} \mathrm{C}$

\begin{tabular}{|c|c|c|c|c|c|c|c|c|c|c|c|c|c|c|c|c|c|}
\hline \multirow{3}{*}{ Material } & \multirow{3}{*}{ Notation } & \multicolumn{8}{|c|}{ Temperature of IGC experiment $35^{\circ} \mathrm{C}$} & \multicolumn{8}{|c|}{ Temperature of IGC experiment $120^{\circ} \mathrm{C}$} \\
\hline & & pentane & hexane & heptane & octane & $\mathrm{CHCl}_{3}$ & Ethanol & Dioxane & $\begin{array}{c}\text { Ethyl } \\
\text { acetate }\end{array}$ & pentane & hexane & heptane & octane & $\mathrm{CHCl}_{3}$ & Ethanol & Dioxane & $\begin{array}{l}\text { Ethyl } \\
\text { acetate }\end{array}$ \\
\hline & & p35 & $\mathrm{x} 35$ & h35 & 035 & c35 & e35 & $\mathrm{d} 35$ & ea35 & p120 & $\mathrm{x} 120$ & h120 & o120 & c120 & $\mathrm{e} 120$ & d120 & ea120 \\
\hline Lithopone & 1 & 0.056 & 0.189 & 0.639 & 2.156 & 0.376 & 1.506 & 1.456 & 0.539 & 0.019 & 0.045 & 0.100 & 0.245 & 0.006 & 0.626 & 1.556 & 0.416 \\
\hline Calfix & $\mathrm{c}$ & 0.366 & 1.150 & 3.660 & 11.033 & 2.177 & 5.527 & 5.517 & 2.683 & 0.389 & 0.729 & 1.379 & 2.579 & 0.959 & 2.759 & 2.559 & 1.729 \\
\hline Pyrite & $\mathrm{p}$ & 0.007 & 0.027 & 0.102 & 0.390 & 0.097 & 1.157 & 0.857 & 0.207 & 0.037 & 0.073 & 0.142 & 0.282 & 0.208 & 0.769 & 0.926 & 0.667 \\
\hline Egzotul & $\mathrm{e}$ & 0.001 & 0.004 & 0.014 & 0.057 & 0.011 & 0.038 & 0.076 & 0.031 & 0.005 & 0.010 & 0.020 & 0.040 & 0.025 & 0.025 & 0.061 & 0.031 \\
\hline PERMON85 & $\mathrm{p} 85$ & 0.033 & 0.105 & 0.356 & 1.614 & 0.264 & 6.056 & 5.281 & 5.481 & 0.011 & 0.021 & 0.061 & 0.103 & 0.114 & 0.231 & 1.881 & 2.481 \\
\hline $\begin{array}{l}\text { Perlite } \\
\text { EXP50 }\end{array}$ & p50 & 0.010 & 0.020 & 0.090 & 0.210 & 0.071 & 0.248 & 1.010 & 1.020 & 0.005 & 0.010 & 0.022 & 0.042 & 0.022 & 0.012 & 0.072 & 0.072 \\
\hline Perlite-150 & p150 & 0.008 & 0.024 & 0.097 & 0.204 & 0.080 & 0.097 & 0.197 & 0.091 & 0.012 & 0.020 & 0.037 & 0.060 & 0.053 & 0.064 & 0.081 & 0.064 \\
\hline $\begin{array}{l}\text { Perlite } \\
\text { EP150 }\end{array}$ & ep150 & 0.015 & 0.031 & 0.071 & 0.143 & 0.071 & 0.104 & 0.131 & 0.087 & 0.011 & 0.020 & 0.045 & 0.077 & 0.042 & 0.056 & 0.073 & 0.057 \\
\hline $\begin{array}{l}\text { Perlite } \\
\text { EP180 }\end{array}$ & ep180 & 0.010 & 0.022 & 0.049 & 0.110 & 0.061 & 0.066 & 0.110 & 0.027 & 0.007 & 0.011 & 0.022 & 0.033 & 0.052 & 0.035 & 0.046 & 0.041 \\
\hline $\begin{array}{l}\text { Perlite } \\
\text { EP200 }\end{array}$ & ep200 & 0.008 & 0.010 & 0.035 & 0.082 & 0.028 & 0.035 & 0.096 & 0.037 & 0.010 & 0.015 & 0.034 & 0.048 & 0.034 & 0.044 & 0.057 & 0.044 \\
\hline $\begin{array}{c}\text { Perlie class } \\
\text { A thick }\end{array}$ & $\mathrm{pA}$ & 0.009 & 0.031 & 0.120 & 0.297 & 0.092 & 0.181 & 0.192 & 0.081 & 0.006 & 0.010 & 0.020 & 0.032 & 0.019 & 0.027 & 0.033 & 0.020 \\
\hline Zeolite fine & $\mathrm{zf}$ & 0.180 & 1.180 & 6.746 & 30.380 & 1.313 & 2.746 & 4.080 & 4.480 & 0.044 & 0.089 & 0.179 & 0.364 & 0.104 & 0.142 & 0.159 & 0.164 \\
\hline Zeolite thick & $\mathrm{zt}$ & 0.039 & 0.150 & 0.575 & 2.125 & 0.235 & 0.250 & 0.450 & 0.346 & 0.017 & 0.034 & 0.067 & 0.134 & 0.039 & 0.059 & 0.056 & 0.071 \\
\hline $\begin{array}{c}\text { Zeolite } \\
\text { micro20 }\end{array}$ & zm20 & 0.020 & 0.082 & 0.349 & 1.621 & 0.171 & 1.138 & 2.355 & 0.538 & 0.005 & 0.010 & 0.025 & 0.046 & 0.035 & 0.108 & 0.113 & 0.074 \\
\hline $\begin{array}{c}\text { Zeolite } \\
\text { micro50 }\end{array}$ & zm50 & 0.028 & 0.138 & 0.622 & 2.322 & 0.231 & 0.628 & 3.028 & 0.628 & 0.009 & 0.019 & 0.039 & 0.083 & 0.068 & 0.111 & 0.278 & 0.205 \\
\hline $\begin{array}{c}\text { Zeolite } \\
\text { ZC20 }\end{array}$ & ZC20 & 0.019 & 0.075 & 0.308 & 1.391 & 0.319 & 1.042 & 0.836 & 0.591 & 0.022 & 0.041 & 0.076 & 0.143 & 0.106 & 0.689 & 0.956 & 0.666 \\
\hline
\end{tabular}


Table 3

Fillers characteristics at 35 and $120^{\circ} \mathrm{C}$

\begin{tabular}{|c|c|c|c|c|c|c|c|c|c|c|c|c|c|c|c|c|c|}
\hline \multirow{3}{*}{ Material } & \multirow{3}{*}{ Notation } & \multicolumn{6}{|c|}{ Temperature of IGC experiment $35^{\circ} \mathrm{C}$} & \multicolumn{6}{|c|}{ Temperature of IGC experiment $120^{\circ} \mathrm{C}$} & \multirow[b]{2}{*}{$\begin{array}{c}\mathrm{BET} \\
{\left[\mathrm{m}^{2} / \mathrm{g}\right]}\end{array}$} & \multirow[b]{2}{*}{$\begin{array}{c}\text { Pore } \\
\text { vol. } \\
{\left[\mathrm{cm}^{3} / \mathrm{g}\right.} \\
]\end{array}$} & \multirow[b]{2}{*}{$\begin{array}{c}\text { Pore } \\
\text { size } \\
{[\AA]}\end{array}$} & \multirow[b]{2}{*}{$\begin{array}{c}\text { Granu } \\
\text { lation } \\
{[\mu \mathrm{m}]}\end{array}$} \\
\hline & & $\begin{array}{c}\gamma_{S}^{D} \\
{\left[\mathrm{~mJ} / \mathrm{m}^{2}\right]}\end{array}$ & $K_{A}$ & $K_{D}$ & $K_{A} / K_{D}$ & $K_{A}+K_{D}$ & $\chi_{23}$ & $\begin{array}{c}\gamma_{S}^{D} \\
{\left[\mathrm{~mJ} / \mathrm{m}^{2}\right]}\end{array}$ & $K_{A}$ & $K_{D}$ & $K_{A} / K_{D}$ & $\begin{array}{c}K_{A}+K \\
D\end{array}$ & $\chi_{23}$ & & & & \\
\hline & & g35 & Ka35 & Kd35 & rK35 & K35 & kh35 & g120 & Ka120 & Kd120 & rK120 & K120 & kh120 & BET & $\mathrm{Vp}$ & $\mathrm{Sp}$ & gra \\
\hline Lithopone & 1 & 60.3 & 0.149 & 0.093 & 1.607 & 0.242 & -0.285 & 32.5 & 0.226 & 0.113 & 1.995 & 0.339 & -3.463 & 3.1 & 0.009 & 16.7 & 56 \\
\hline Calfix & $\mathrm{c}$ & 52.7 & 0.125 & 0.086 & 1.454 & 0.211 & -0.035 & 26.2 & 0.121 & 0.083 & 1.450 & 0.205 & -0.027 & 1.3 & 0.005 & 18.1 & 56 \\
\hline Pyrite & $\mathrm{p}$ & 72.9 & 0.216 & 0.165 & 1.304 & 0.381 & -0.719 & 30.1 & 0.194 & 0.213 & 0.910 & 0.407 & -2.132 & 2.5 & 0.006 & 11.4 & 65 \\
\hline Egzotul & $\mathrm{e}$ & 69.9 & 0.190 & 0.132 & 1.442 & 0.322 & -4.934 & 31.6 & 0.142 & 0.142 & 0.995 & 0.284 & -8.863 & 4.1 & 0.004 & 39.7 & 50 \\
\hline PERMON85 & $\mathrm{p} 85$ & 65.3 & 0.224 & 0.111 & 2.013 & 0.335 & -5.303 & 40.4 & 0.284 & 0.240 & 1.182 & 0.523 & -6.148 & 8.8 & 0.046 & 206.0 & 85 \\
\hline $\begin{array}{l}\text { Perlite } \\
\text { EXP50 }\end{array}$ & p50 & 45.3 & 0.205 & 0.125 & 1.639 & 0.330 & -3.232 & 33.9 & 0.151 & 0.121 & 1.248 & 0.272 & -4.547 & 2.2 & 0.002 & 106.6 & 50 \\
\hline Perlite-150 & $\mathrm{p} 150$ & 48.5 & 0.141 & 0.141 & 1.002 & 0.282 & -3.151 & 19.6 & 0.109 & 0.144 & 0.752 & 0.253 & -4.362 & 2.8 & 0.005 & 93.8 & 150 \\
\hline $\begin{array}{l}\text { Perlite } \\
\text { EP150 } \\
\end{array}$ & ep150 & 36.2 & 0.122 & 0.129 & 0.936 & 0.251 & -3.042 & 29.4 & 0.110 & 0.109 & 1.010 & 0.219 & -4.153 & 1.6 & 0.003 & 310.4 & 250 \\
\hline $\begin{array}{l}\text { Perlite } \\
\text { EP180 }\end{array}$ & ep180 & 42.1 & 0.138 & 0.158 & 0.873 & 0.297 & -3.374 & 19.0 & 0.108 & 0.223 & 0.484 & 0.331 & -4.427 & 1.6 & 0.006 & 377.8 & 800 \\
\hline $\begin{array}{l}\text { Perlite } \\
\text { EP200 }\end{array}$ & ep200 & 48.4 & 0.152 & 0.130 & 1.163 & 0.282 & -3.522 & 20.5 & 0.102 & 0.110 & 0.926 & 0.211 & -4.732 & 0.7 & 0.002 & 234.1 & 1000 \\
\hline $\begin{array}{c}\text { Perlite class } \\
\text { A thick }\end{array}$ & $\mathrm{pA}$ & 54.9 & 0.135 & 0.134 & 1.007 & 0.269 & -4.112 & 21.7 & 0.099 & 0.094 & 1.062 & 0.194 & -5.3616 & 1.8 & 0.004 & 222.4 & 2000 \\
\hline Zeolite fine & $\mathrm{zf}$ & 122.0 & 0.146 & 0.041 & 3.596 & 0.187 & -7.234 & 32.6 & 0.078 & 0.033 & 2.370 & 0.110 & -20.132 & 174.4 & 0.373 & 125.3 & 2000 \\
\hline Zeolite thick & $\mathrm{zt}$ & 74.3 & 0.118 & 0.068 & 1.744 & 0.186 & -6.942 & 31.1 & 0.073 & 0.031 & 2.376 & 0.103 & -19.254 & 153.4 & 0.264 & 96.7 & 1200 \\
\hline $\begin{array}{l}\text { Zeolite } \\
\text { micro20 }\end{array}$ & $\mathrm{zm} 20$ & 84.0 & 0.211 & 0.096 & 2.208 & 0.307 & -5.323 & 38.1 & 0.176 & 0.184 & 0.956 & 0.359 & -1.158 & 30.911 & 0.118 & 176.3 & 20 \\
\hline $\begin{array}{c}\text { Zeolite } \\
\text { micro50 }\end{array}$ & $\mathrm{zm} 50$ & 84.9 & 0.204 & 0.080 & 2.548 & 0.284 & -5.876 & 35.9 & 0.191 & 0.196 & 0.976 & 0.387 & -0.532 & 28.924 & 0.125 & 208.3 & 50 \\
\hline $\begin{array}{c}\text { Zeolite } \\
\text { ZC20 }\end{array}$ & ZC20 & 80.1 & 0.171 & 0.175 & 0.978 & 0.345 & -5.238 & 25.590 & 0.208 & 0.146 & 1.421 & 0.354 & -3.948 & 27.063 & 0.113 & 190.6 & 50 \\
\hline
\end{tabular}




\section{Captions to figures}

Figure 1

Unrotated principal component loadings for retention data

\section{Figure 2}

Results of cluster analysis for retention data (Euclidean distance and Ward's method was used)

Figure 3

Sum of ranking differences (rescaled values between 0 and 100: $\mathrm{x}$ axis and left y axis) for retention data. The ranking is far from being random; the lower tail of Gauss distribution fitted to the random values can be seen in the lower right corner, right y axis)

Figures $4 \mathrm{a}, 4 \mathrm{~b}$ and $4 \mathrm{c}$

Score plots (various projections) according retention times

Figure 5

Unrotated principal component loadings for physicochemical parameters

Figure 6

Results of cluster analysis for physicochemical parameters (Euclidean distance and Ward's method was used)

Figure 7

Sum of ranking differences (rescaled values between 0 and 100: $\mathrm{x}$ axis and left y axis) for physicochemical parameters.

Figure 8

Score plots (various projections) for physicochemical parameters 
Figure 1

Factor Loadings, Factor 1 vs. Factor 2 vs. Factor 3

Rotation: Unrotated

Extraction: Principal components

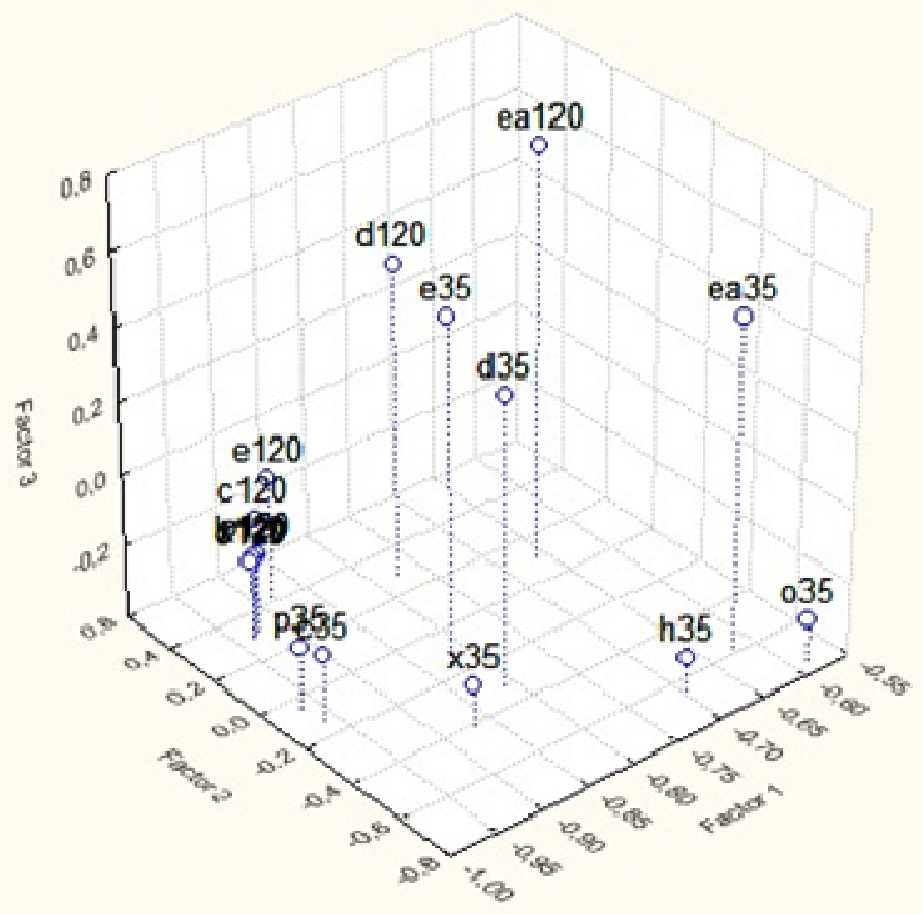


Figure 2

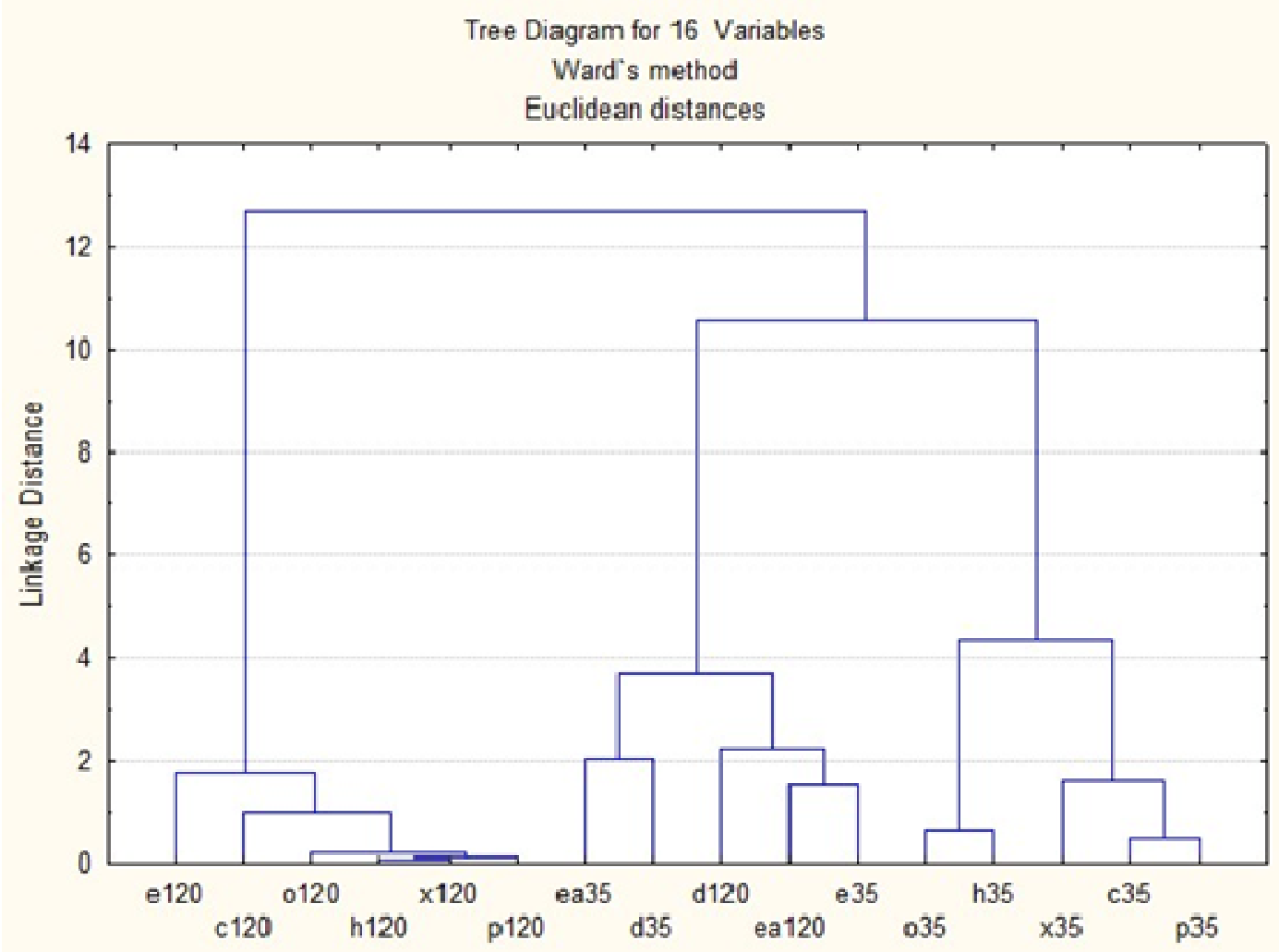


Figure 3

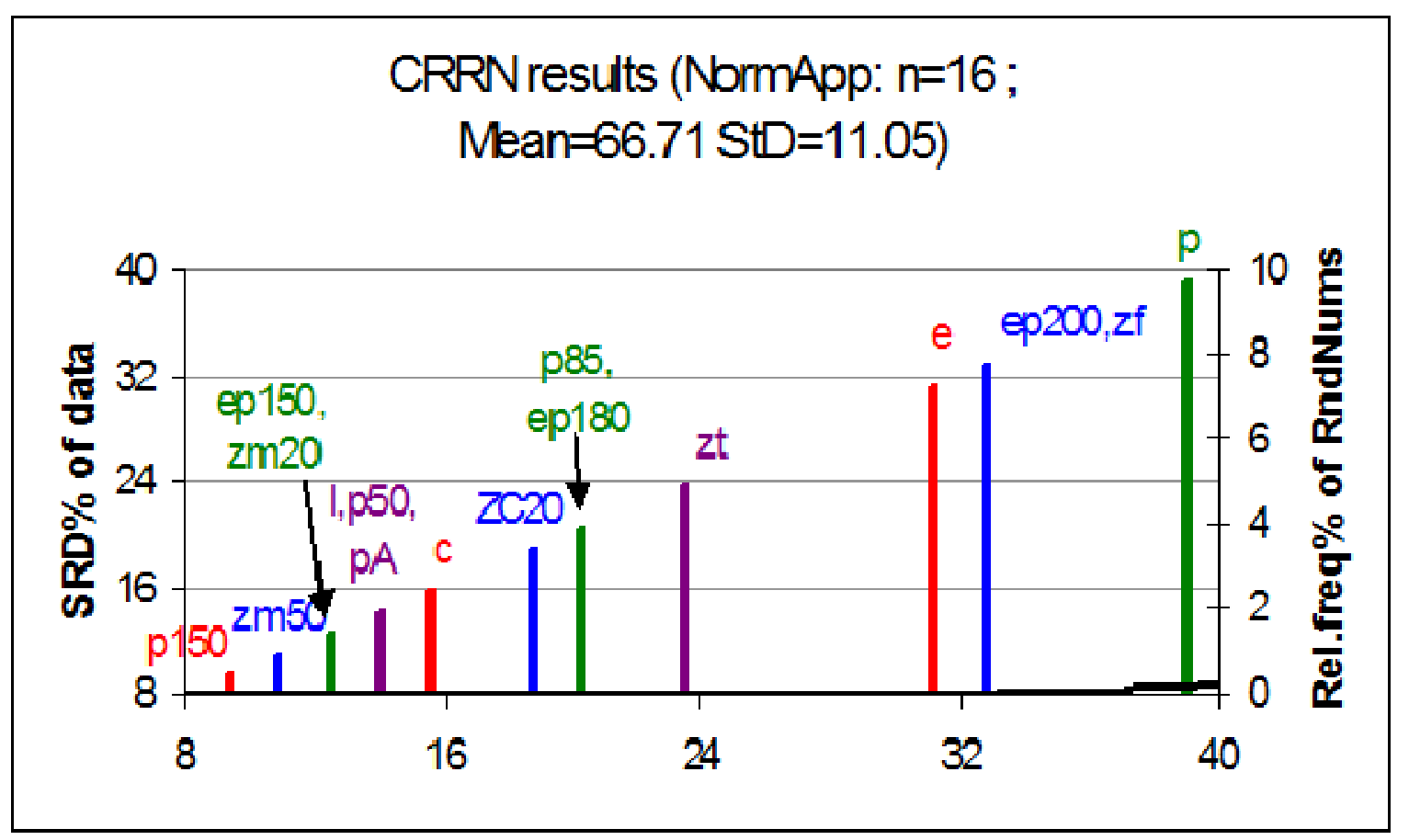


Figures 4a, 4b, 4c,
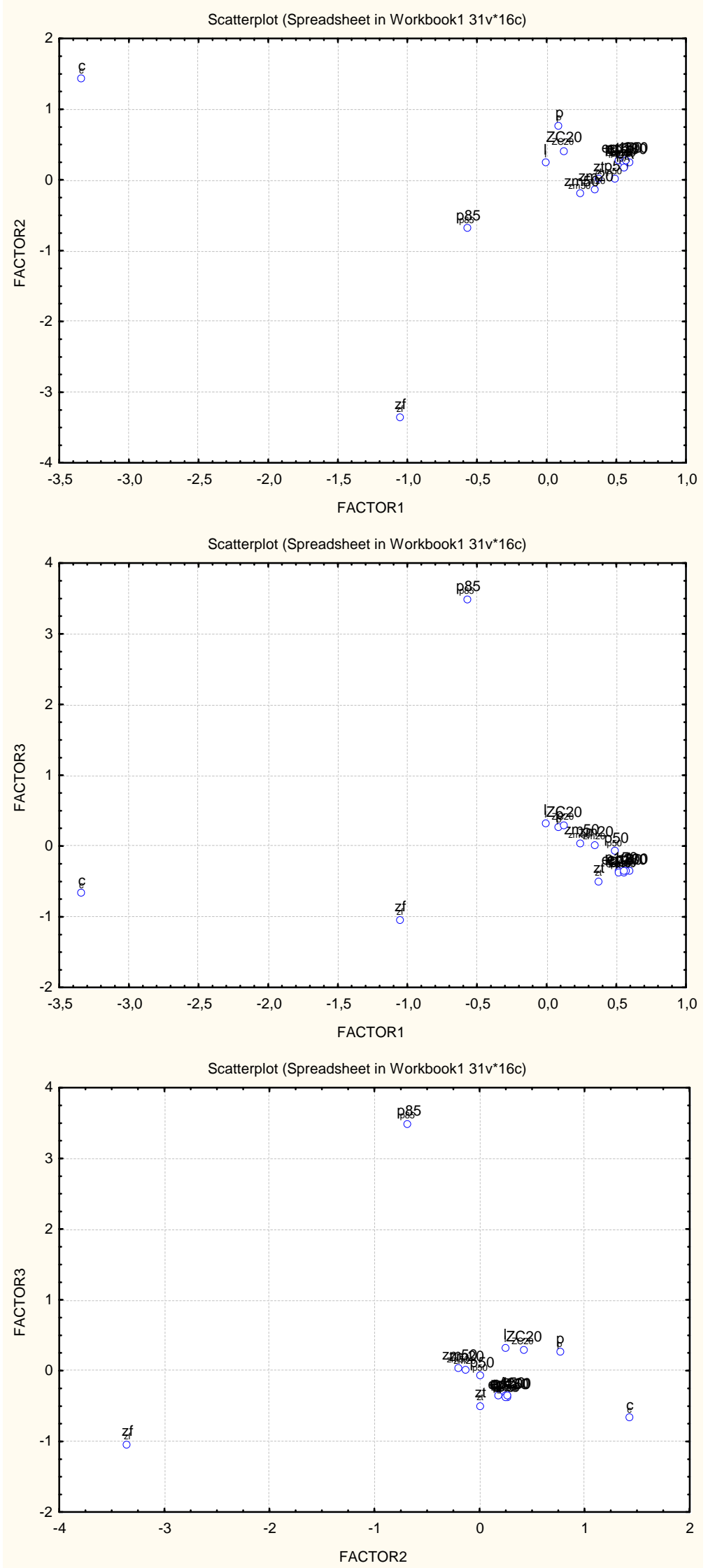
Figure 5

Factor Loadings, Factor 1 vs. Factor 2 vs. Factor 3

Rotation: Unrotated

Extraction: Principal components

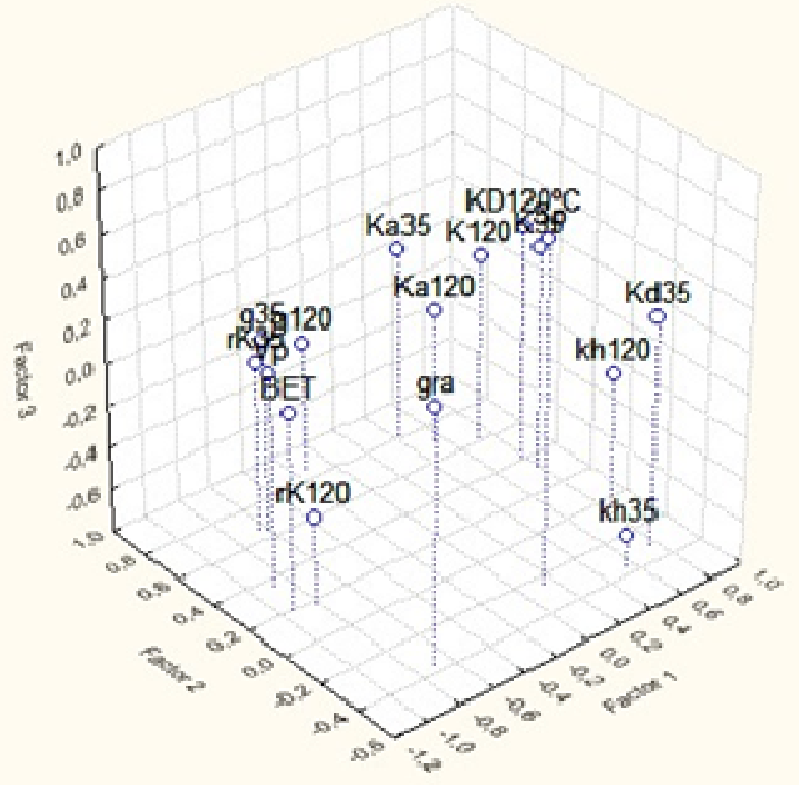


Figure 6

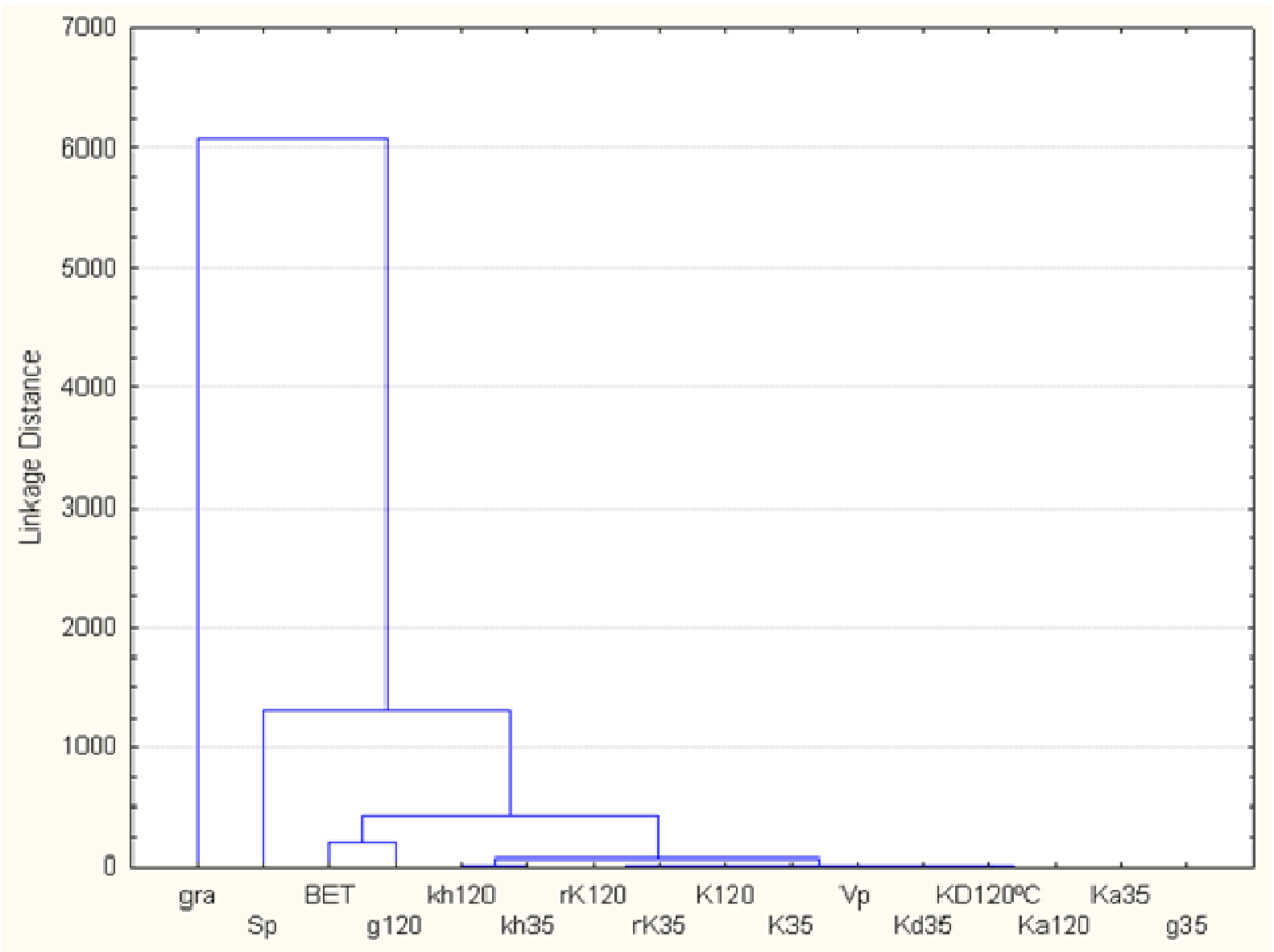


Figure 7

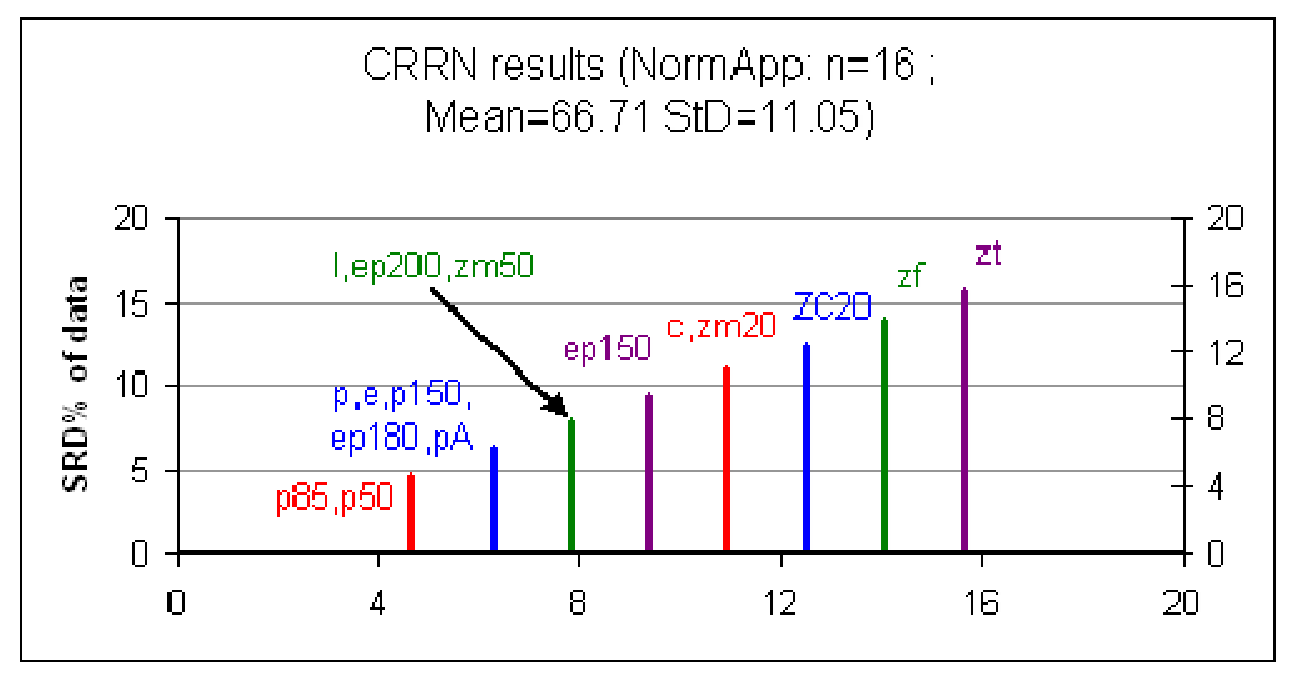


Figures $8 \mathrm{a}, 8 \mathrm{~b}$, and 8c.
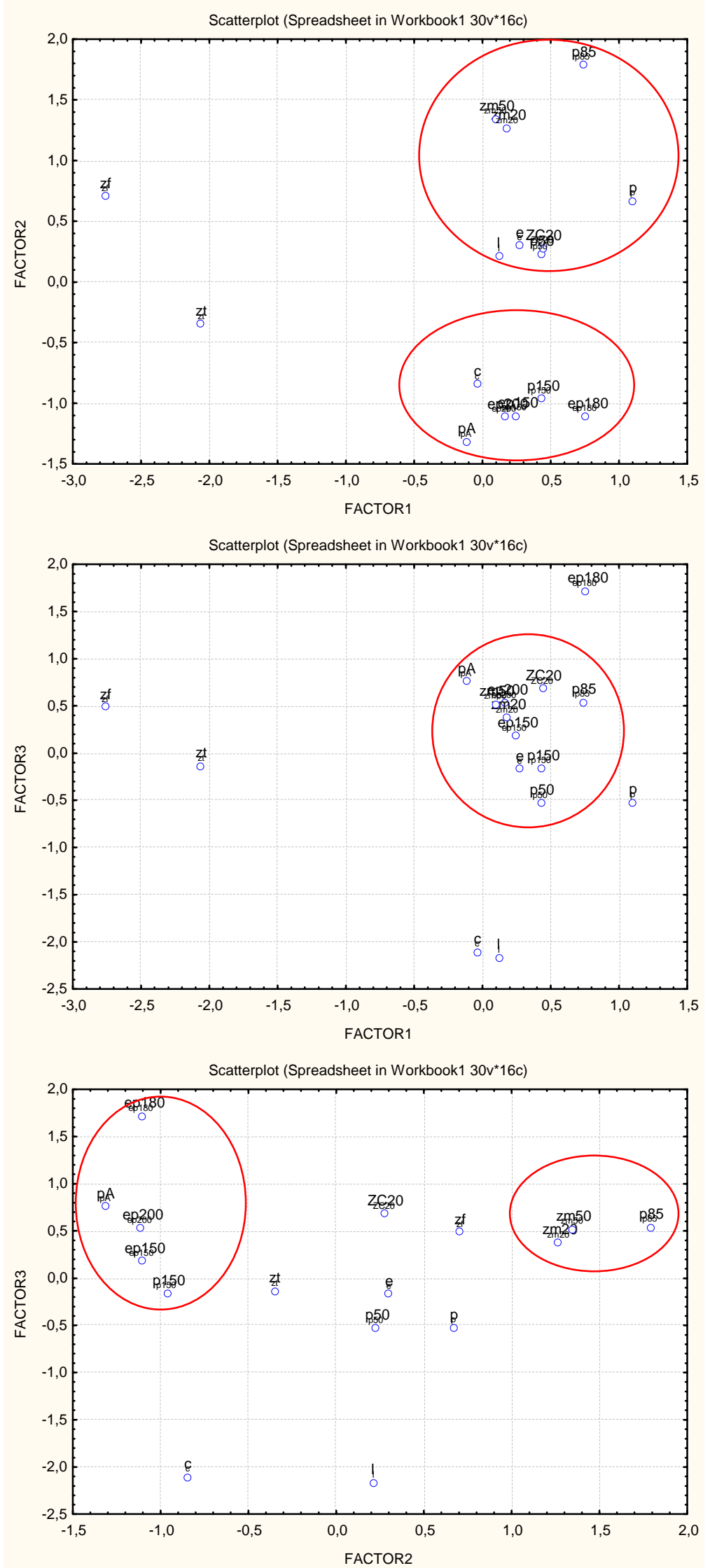